Published in final edited form as:

Chem Res Toxicol. 2011 April 18; 24(4): 478-480. doi:10.1021/tx200060c.

\title{
Direct Analysis of Methylated Trivalent Arsenicals in Mouse Liver by Hydride Generation-Cryotrapping-Atomic Absorption Spectrometry
}

\author{
Jenna M. Currier ${ }^{\dagger}$, Milan Svoboda ${ }^{\ddagger}$, , Diogo P. de Moraes ${ }^{\ddagger, \|}$, Tomáš Matoušek ${ }^{\ddagger}$, Jiří \\ Dědina $\ddagger$, and Miroslav Stýblo ${ }^{\perp,}$ \\ ${ }^{\dagger}$ Curriculum in Toxicology, University of North Carolina at Chapel Hill, North Carolina, United \\ States \\ \#Institute of Analytical Chemistry of the ASCR, v.v.i., Brno, Czech Republic \\ §Department of Analytical Chemistry, Faculty of Science, Charles University in Prague, Prague, \\ Czech Republic \\ "Instituto de Química, Universidade Federal do Rio Grande do Sul, Porto Alegre, RS, Brazil \\ ${ }^{\perp}$ Department of Nutrition, University of North Carolina at Chapel Hill, North Carolina, United \\ States
}

\section{Abstract}

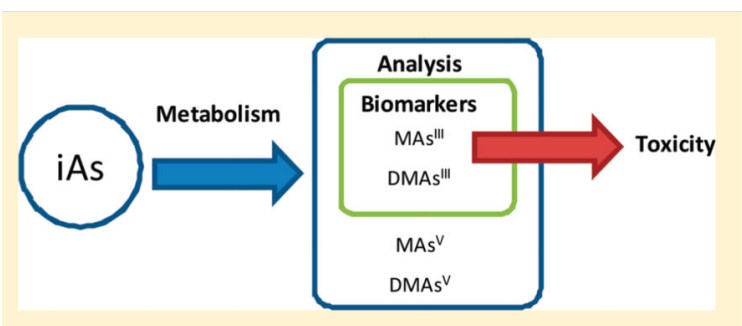

Growing evidence suggest that the methylated trivalent metabolites of inorganic arsenic (iAs), methylarsonite (MAs ${ }^{\mathrm{III}}$ ) and dimethylarsinite (DMAs ${ }^{\mathrm{III}}$ ), contribute to adverse effects of iAs exposure. However, the lack of suitable methods has hindered the quantitative analysis of MAs III and DMAs ${ }^{\mathrm{III}}$ in complex biological matrices. Here, we show that hydride generation-cryotrappingatomic absorption spectrometry can quantify both MAs ${ }^{\mathrm{III}}$ and DMAs ${ }^{\mathrm{III}}$ in livers of mice exposed to iAs. No sample extraction is required, thus limiting MAs ${ }^{\mathrm{III}}$ or DMAs ${ }^{\mathrm{III}}$ oxidation prior to analysis. The limits of detection are below $6 \mathrm{ng}$ As/g of tissue, making this method suitable even for studies examining low exposures to iAs.

(C2011 American Chemical Society

*Corresponding Author. Tel: 919-966-5721. Fax: 919-843-0776. styblo@med.unc.edu. ASSOCIATED CONTENT

Supporting Information. Detailed experimental section including analytical procedures, characteristics of calibration curves, and detection limits. This material is available free of charge via the Internet at http://pubs.acs.org. 
Inorganic arsenic (iAs), a carcinogenic metalloid found in the earth's crust, can accumulate in aquifers naturally or due to industrial activities. ${ }^{1}$ Chronic iAs exposure through contaminated drinking water has been linked to risks of various diseases, including cancer, hypertension, and diabetes. ${ }^{2-4}$ The individual susceptibility to these diseases varies considerably, even at similar exposure levels, complicating the risk assessment. Current evidence suggest that the trivalent methylated metabolites of iAs, methylarsonite (MAs ${ }^{\mathrm{III}}$ ) and dimethylarsinite (DMAs ${ }^{\mathrm{III}}$ ), are more toxic than pentavalent methylarsonate (MAs ${ }^{\mathrm{V}}$ ) and dimethylarsinate $\left(\mathrm{DMAs}^{\mathrm{V}}\right)$ ), or iAs species, arsenite $\left(\mathrm{iAs}{ }^{\mathrm{III}}\right)$ and arsenate $\left(\mathrm{iAs}{ }^{\mathrm{V}}\right) .{ }^{5}$ Both MAs ${ }^{\mathrm{III}}$ and DMAs ${ }^{\mathrm{III}}$ are products of iAs methylation by arsenic ( +3 oxidation state) methyltransferase ${ }^{6}$ and by cultured human hepatocytes. ${ }^{7}$ Both MAs ${ }^{\mathrm{III}}$ and DMAs ${ }^{\mathrm{III}}$ are present in the urine of individuals exposed to iAs in drinking water. ${ }^{8}$ However, results of recent studies indicate that the concentrations and proportion of iAs metabolites in urine do not necessarily reflect the concentrations and speciation of As in tissues targeted by iAs exposure. ${ }^{9-11}$ Other studies demonstrate an organ specific accumulation of iAs and methylated arsenicals after exposure to iAs. ${ }^{12}$ Thus, the quantitative analysis of iAs metabolites in target tissues is crucial for elucidating the mechanisms of the adverse effects of iAs exposure and for understanding the interindividual variations in manifestation and severity of the diseases associated with this exposure.

Several methods have been developed for the speciation analysis of As in aqueous samples, including human urine. ${ }^{13-15}$ However, only hydride generation-cryotrapping-atomic absorption spectroscopy (HG-CT-AAS) is uniquely suited for the oxidation state specific analysis of As in complex biological matrices. ${ }^{6,16,17}$ Unlike HPLC techniques, HG-CT-AAS does not require digestion or extraction of biological samples and, therefore, limits the artifacts associated with the oxidation or with on-column binding of the reactive, but unstable methylated trivalent metabolites. ${ }^{18}$ We have previously used HG-CT-AAS for quantitative analysis of iAs metabolites, including MAs ${ }^{\mathrm{III}}$ and DMAs ${ }^{\mathrm{III}}$ in cultured mammalian cells capable of methylating iAs. ${ }^{6}$ Here, speciation analysis of As is carried out in two sample aliquots. In the first aliquot, hydrides (arsine and methyl-sub-stituted arsines) from the trivalent As species (iAs ${ }^{\mathrm{III}}, \mathrm{MAs}{ }^{\mathrm{III}}$, and DMAs ${ }^{\mathrm{III}}$ ) are selectively generated at $\mathrm{pH} 6$ and measured directly without sample pretreatment. The second aliquot is treated with $2 \%$ Lcysteine to reduce the pentavalent As species (iAs ${ }^{\mathrm{V}}, \mathrm{MAs}^{\mathrm{V}}$, and $\mathrm{DMAs}{ }^{\mathrm{V}}$ ) to trivalency; thus, arsines generated from this sample aliquot represent both tri- and pentavalent As species (iAs ${ }^{\mathrm{III}+\mathrm{V}}, \mathrm{MAs}^{\mathrm{III}+\mathrm{V}}$, and DMAs ${ }^{\mathrm{III}+\mathrm{V}}$ ) present in the sample. The concentrations of the pentavalent As species are then determined by subtracting the results of analysis in the first sample aliquot from results of the analysis in the second aliquot. (See Supporting Information for technical details.) The goal of the present study was to examine whether this HG-CT-AAS technique is also suitable for quantitative, oxidation state specific analysis of As species in tissues.

In the first step, we compared the efficiency of generation of As species in aqueous solutions and in mouse livers. Here, we used the liver from an untreated mouse fed a regular diet and drinking deionized water (DIW). Ten percent liver homogenates (w/v) were prepared in DIW on ice and spiked with iAs ${ }^{\mathrm{V}}, \mathrm{MAs}^{\mathrm{V}}$, and DMAs ${ }^{\mathrm{V}}$ standards to generate calibration curves. In parallel, calibration curves were generated for solutions of these standards in DIW. Both, the aqueous standard solutions and the spiked homogenates were treated with 
$2 \%$ L-cysteine and analyzed by HG-CT-AAS ${ }^{6,16,17}$ using an AAnalyst800 atomic absorption spectrometer equipped with a FIAS400 flow injection accessory (PerkinElmer Norwalk, CT, USA). We found that the slopes of the calibration curves generated for the aqueous standards and spiked homogenates are very similar (Table S1, Supporting Information), suggesting that the complex matrix of the liver homogenate does not interfere with the analysis.

In the second step, we compared the recovery of As standards from a liver homogenate and aqueous solutions. Here, a mixture of pentavalent $\mathrm{iAs}{ }^{\mathrm{V}}, \mathrm{MAs}^{\mathrm{V}}$, and DMAs ${ }^{\mathrm{V}}$ standards (10 ng As each) and individual trivalent iAs ${ }^{\mathrm{III}}$, MAs ${ }^{\mathrm{III}}$, and DMAs ${ }^{\mathrm{III}}$ standards (10 ng As each) were prepared in DIW or in a $10 \%$ liver homogenate from an untreated mouse and analyzed with or without L-cysteine pretreatment. Figure 1 shows that, regardless of the matrix, the trivalent arsenicals can be quantitatively analyzed in the absence or presence of $\mathrm{L}_{\mathrm{L}} \mathrm{cysteine}$ with As recoveries of $\sim 92-105 \%$. Lower As recoveries were found only for homogenates spiked with iAs ${ }^{\mathrm{III}}(\sim 80 \%)$ or DMAs ${ }^{\mathrm{III}}(\sim 72 \%)$ that were not treated with ${ }_{\text {L-cysteine. In }}$ contrast, the pentavalent arsenicals were detected only after the prereduction with ${ }_{\mathrm{L}}$-cysteine. Consistent with our previous findings, ${ }^{17}$ only DMAs ${ }^{\mathrm{V}}$ generated a small amount of dimethylarsine ( $\sim 6-7 \%$ of total As) in the absence of $\mathrm{L}_{\mathrm{L}} \mathrm{cysteine}$. The recoveries of As for DIW and homogenates spiked with pentavalent standards ranged from $\sim 90$ to $102 \%$. Detection limits calculated for a blank liver homogenate with and without $\mathrm{L}$-cysteine pretreatment ranged from 9 to $14 \mathrm{pg}$ As, which translate to $5 \mathrm{ng}$ As/g of the tissue (Table S2, Supporting Information).

Finally, we used HG-CT-AAS to determine the concentrations of As species in the liver of a mouse exposed to iAs ${ }^{\mathrm{III}}$ in drinking water $(50 \mathrm{mg}$ As/L) for 9 days. Here, the freshly dissected liver was divided into 4 sections. Each section was homogenized in ice-cold DIW. Aliquots of the $10 \%$ homogenates were immediately analyzed for As ${ }^{\mathrm{III}}$ species (without $\mathrm{L}_{\text {- }}$ cysteine pretreatment) and for $\mathrm{As}^{\mathrm{III}+\mathrm{V}}$ species (after pretreatment with $\mathrm{L}$-cysteine). Additional aliquots from each liver section were digested in phosphoric acid for $10 \mathrm{~h}$ at 90 ${ }^{\circ} \mathrm{C}$ using the MARS5 microwave system. ${ }^{19}$ This digestion eliminates the biological matrix and oxidizes all trivalent As species to pentavalency. ${ }^{20}$ Thus, only the total iAs (iAs ${ }^{\mathrm{III}+\mathrm{V}}$ ), MAs (MAs ${ }^{\mathrm{III}+\mathrm{V}}$ ), and DMAs (DMAs ${ }^{\mathrm{III}+\mathrm{V}}$ ) can be measured in the digested samples. Table 1 compares results of the direct speciation analysis and analysis of the digested homogenate from one of the liver sections. On the basis of the direct analysis, MAs ${ }^{\mathrm{III}}$ and DMAs ${ }^{\mathrm{III}}$ represented, respectively, $12 \%$ and $45 \%$ of the total speciated As, while their pentavalent counterparts, $\mathrm{MAs}^{\mathrm{V}}$ and DMAs ${ }^{\mathrm{V}}$, accounted for $8 \%$ and $18 \%$, respectively. Notably, the sums of tri- and pentavalent MAs and DMAs determined by the direct analysis were in a good agreement with the concentrations of MAs ${ }^{\mathrm{III}+\mathrm{V}}$ and DMAs ${ }^{\mathrm{III}+\mathrm{V}}$ determined in the digested homogenates. However, the amount of iAs recovered during the direct analysis represented only $\sim 79 \%$ of iAs recovered after the digestion. Figure 2 shows the recoveries of iAs, MAs, and DMAs in directly analyzed homogenates from all 4 sections of the liver as compared to the analyses in digested homogenates. Here, the direct analysis recovered approximately $99 \%$ of total As, with individual recoveries of $83 \pm 5 \%$ for iAs ${ }^{\mathrm{III}+\mathrm{V}}, 100 \pm$ $6 \%$ for MAs ${ }^{\mathrm{III}+\mathrm{V}}$, and $107 \pm 1 \%$ for DMAs ${ }^{\mathrm{III}+\mathrm{V}}$. Together with the data in Table 1 , these results suggest high As recoveries and a good reproducibility of the speciation analysis in liver homogenates. 
In conclusion, this work shows that HG-CT-AAS is suitable for the quantitative, oxidation state specific analysis of As species, including the unstable MAs ${ }^{\mathrm{III}}$ and DMAs ${ }^{\mathrm{III}}$, in mammalian tissues. Our data show that approximately $66 \%$ of As in the liver of a mouse exposed to iAs is represented by trivalent species; $\sim 12 \%$ by MAs ${ }^{\mathrm{III}}$ and $\sim 45 \%$ by DMAs ${ }^{\mathrm{III}}$. These results further strengthen the hypothesis that methylated trivalent arsenicals contribute to the adverse effects in tissues targeted by iAs exposure. Additional optimization may be needed to improve recoveries of iAs, which are likely bound to high-affinity binding sites in tissue homogenates, and to prevent the oxidation of DMAs ${ }^{\mathrm{III}}$, which contributes to lower recoveries of this unstable As species.

\section{Supplementary Material}

Refer to Web version on PubMed Central for supplementary material.

\section{Acknowledgments}

Funding Sources

GIL grant 200710.0028; NIH grant DK056350, Czech Science Foundation grant 203/09/1783, and IAC ASCR project No. AV0Z40310501.

\section{ABBREVIATIONS}

iAs

MAs ${ }^{\text {III }}$

DMAs III

MAs $V$

DMAs

iAs ${ }^{\text {III }}$

iAs $\mathrm{V}$

As ${ }^{\text {III }}$

As $\mathbf{V}$

HG-CT-AAS

DIW inorganic arsenic

methylarsonite

dimethylarsinite

methylarsonate

dimethylarsinate

arsenite

arsenate

trivalent arsenic

pentavalent arsenic

deionized water

\section{REFERENCES}

1. Smedley PL, Kinniburgh DG. Appl. Geochem. 2002; 17:517-568.

2. IARC Working Group on the Evaluation of Carcinogenic Risks to Humans. IARC Monogr. Eval. Carcinog. Risks Hum. 2004; 84:1-477. [PubMed: 15645577]

3. Wang CH, Hsiao CK, Chen CL, Hsu LI, Chiou HY, Chen SY, Hsueh YM, Wu MM, Chen CJ. Toxicol. Appl. Pharmacol. 2007; 222:315-326. [PubMed: 17433393]

4. Navas-Acien A, Silbergeld EK, Streeter RA, Clark JM, Burke TA, Guallar E. Environ. Health Perspect. 2006; 114:641-648. [PubMed: 16675414]

5. Thomas DJ, Styblo M, Lin S. Toxicol. Appl. Pharmacol. 2001; 176:127-144. [PubMed: 11601889] 
6. Hernandez-Zavala A, Matousek T, Drobna Z, Paul DS, Walton F, Adair BM, Dedina J, Thomas DJ, Styblo M. J. Anal. At. Spectrom. 2008; 23:342-351. [PubMed: 18677417]

7. Devesa V, Maria DR, Adair B, Drobna Z, Waters SB, Hughes MF, Styblo M, Thomas DJ. J. Anal. At. Spectrom. 2004; 19:1460-1467.

8. Valenzuela OL, Borja-Aburto VH, Garcia-Vargas GG, Cruz-Gonzalez MB, Garcia-Montalvo EA, Calderon-Aranda ES, Del Razo LM. Environ. Health Perspect. 2005; 113:250-254. [PubMed: 15743710]

9. Kenyon EM, Del Razo LM, Hughes MF, Kitchin KT. Toxicology. 2005; 206:389-401. [PubMed: 15588929]

10. Kenyon EM, Del Razo LM, Hughes MF. Toxicol. Sci. 2005; 85:468-475. [PubMed: 15703264]

11. Hernandez-Zavala A, Valenzuela OL, Matousek T, Drobna Z, Dedina J, Garcia-Vargas GG, Thomas DJ, Del Razo LM, Styblo M. Environ. Health Perspect. 2008; 116:1656-1660. [PubMed: 19079716]

12. Kenyon EM, Hughes MF, Adair BM, Highfill JH, Crecelius EA, Clewell HJ, Yager JW. Toxicol. Appl. Pharmacol. 2008; 232:448-455. [PubMed: 18706920]

13. Gong ZL, Lu XF, Cullen WR, Le XC. J. Anal. At. Spectrom. 2001; 16:1409-1413.

14. Suzuki KT, Mandal BK, Ogra Y. Talanta. 2002; 58:111-119. [PubMed: 18968738]

15. Sampayo-Reyes A, Zakharyan RA, Healy SM, Aposhian HV. Chem. Res. Toxicol. 2000; 13:11811186. [PubMed: 11087441]

16. Del Razo LM, Styblo M, Cullen WR, Thomas DJ. Toxicol. Appl. Pharmacol. 2001; 174:282-293. [PubMed: 11485389]

17. Matousek T, Hernandez-Zavala A, Svoboda M, Langrova L, Adair BM, Drobna Z, Thomas DJ, Styblo M, Dedina J. Spectrochim. Acta, Part B At. Spectrosc. 2008; 63:396-406. [PubMed: 18521190]

18. Raab A, Meharg AA, Jaspars M, Genney DR, Feldmann J. J. Anal. At. Spectrom. 2004; 19:183190.

19. Hughes MF, Edwards BC, Herbin-Davis KM, Saunders J, Styblo M, Thomas DJ. Toxicol. Appl. Pharmacol. 2010; 249:217-223. [PubMed: 20887743]

20. Hughes MF, Devesa V, Adair BM, Styblo M, Kenyon EM, Thomas DJ. Toxicol. Appl. Pharmacol. 2005; 208:186-197. [PubMed: 16183392] 

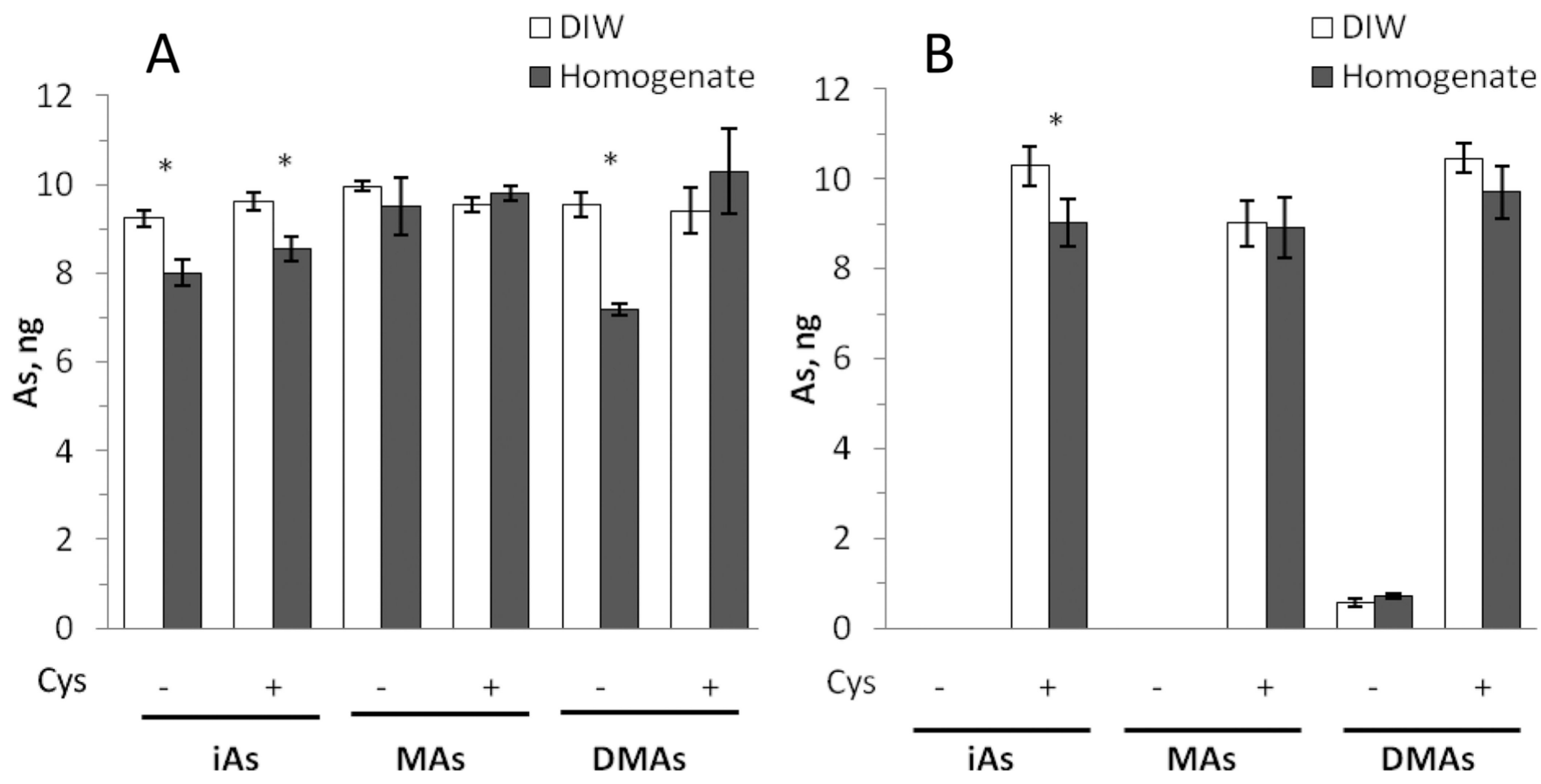

Figure 1.

HG-CT-AAS analysis of DIW and $10 \%$ liver homogenate spiked with $\mathrm{As}^{\mathrm{III}}$ (A) and $\mathrm{As}^{\mathrm{V}}$ (B) standards. DIW and aliquots of the homogenate were spiked with a mixture of $\mathrm{As}^{\mathrm{V}}$ standards (10 ng each) or with individual As ${ }^{\mathrm{III}}$ standards (10 ng each) and analyzed before and after pretreatment with $2 \%$ L-cysteine (Cys) (mean $\pm \mathrm{SD}, n=3$ ). *Statistically significant differences $(p<0.05)$ between the amounts of an As species detected in DIW and in the homogenate as determined by ANOVA with a Bonferroni multiple comparison posttest. 

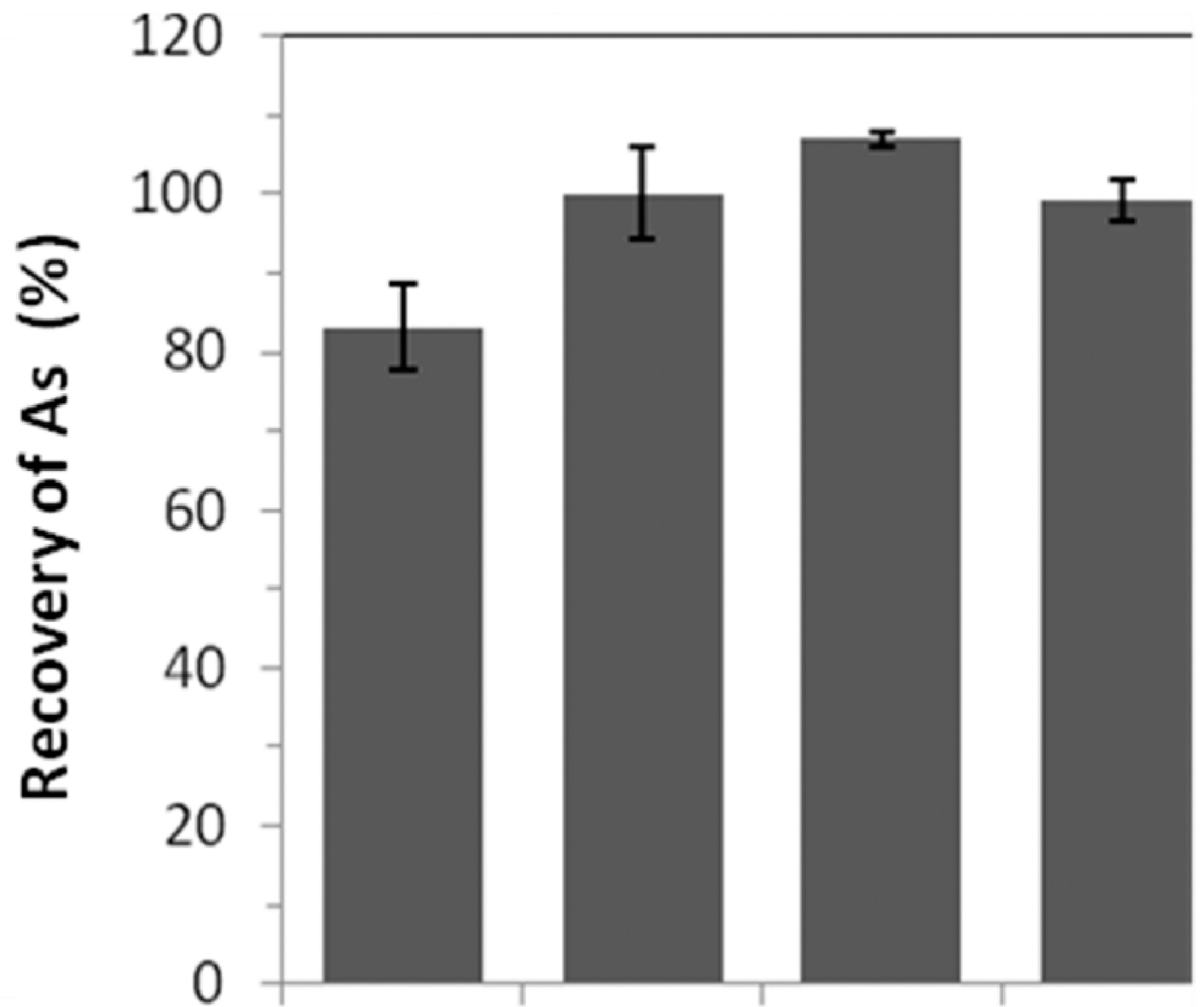

\section{iAs}

MAs

DMAs

Total

Figure 2.

Recovery of total speciated As during the direct analyses of fresh (undigested) homogenates prepared from 4 sections of the liver of a mouse exposed to iAs ${ }^{\mathrm{III}}$ (50 ppm As) for 9 days (mean $\pm \mathrm{SD}, n=4$ ). The homogenates were analyzed by HG-CT-AAS as described for Figure 1 . The $\%$ recovery was calculated as $\left(\mathrm{As}^{\mathrm{III}+\mathrm{V}}\right.$ analyzed directly/As ${ }^{\mathrm{III}+\mathrm{V}}$ after digestion) $\times 100$. 


\section{Table 1}

Concentration of As Species in One Section of the Liver (ng As/g of Tissue) from a Mouse Exposed to iAs ${ }^{\mathrm{III}}$ in Drinking Water (50 ppm As) for 9 Days $^{a}$

\begin{tabular}{|c|c|c|c|c|}
\hline \multirow[b]{2}{*}{ As species } & \multirow{2}{*}{$\begin{array}{r}\text { analysis of digested } \\
\text { liver homogenate } b \\
\text { ng As/g of tissue }\end{array}$} & \multicolumn{2}{|c|}{$\begin{array}{c}\text { direct analysis of fresh liver } \\
\text { homogenate }^{c}\end{array}$} & \\
\hline & & ng As/g of tissue & $\%$ recovery $d$ & \\
\hline iAs $s^{I I I}$ & & $151 \pm 15$ & & \\
\hline $\mathrm{iAs}^{\mathrm{V}}$ & & $158 \pm 16$ & & \\
\hline $\mathrm{iAs} s^{\mathrm{III+V}}$ & $392 \pm 12$ & $309 \pm 7$ & $79 \pm 3$ & \\
\hline MAs ${ }^{I I I}$ & & $220 \pm 5$ & & \\
\hline MAs $^{\mathrm{V}}$ & & $143 \pm 6$ & & \\
\hline MAs ${ }^{I I I+V}$ & $390 \pm 1$ & $363 \pm 4$ & $93 \pm 1$ & \\
\hline DMAs ${ }^{I I I}$ & & $828 \pm 11$ & & \\
\hline DMAs $^{\mathrm{V}}$ & & $324 \pm 16$ & & \\
\hline DMAs $s^{I I I+V}$ & $1069 \pm 10$ & $1152 \pm 11$ & $108 \pm 2$ & \\
\hline total $\mathbf{A s} \mathbf{s I I + V}^{\mathrm{III}}$ & $1851 \pm 16$ & $1824 \pm 14$ & $99 \pm 1$ & \\
\hline \multicolumn{5}{|c|}{$\begin{array}{l}{ }^{a} \text { Results of the direct analysis of fresh liver homogenate and the homogenate digested in phosphoric acid. A total of } 9 \text { aliquots of the homogenate } \\
\text { prepared from } 1 \text { section of the liver was analyzed by HG-CT-AAS. }\end{array}$} \\
\hline \multicolumn{5}{|c|}{$\begin{array}{l}b \text { Three aliquots were microwave digested in phosphoric acid at } 90{ }^{\circ} \mathrm{C} \text { for } 10 \mathrm{~h} \text { and analyzed for As }{ }^{\mathrm{III}}+\mathrm{V} \text { species. (Mean } \pm \mathrm{SD} \text { are shown for } n= \\
\text { 3.) }\end{array}$} \\
\hline
\end{tabular}

